

\title{
19 Work Disability and Health over the Life Course
}

\author{
Axel Börsch-Supan and Henning Roth
}

\subsection{Work disability across European countries}

Disability insurance - the insurance against the loss of the ability to work - is a substantial part of social security expenditures and an important part of the welfare state regime in all developed countries (Aarts et al., 1996). Like almost all elements of modern social security systems, disability insurance faces a trade-off. On the one hand, disability insurance protects unhealthy people who are not able to work from falling into poverty before they are eligible for normal retirement benefits. On the other hand, however, disability insurance creates incentives to exit the labour force early and may act as another pathway to early retirement without the incidence of a major health loss.

The recipiency rates of disability insurance (DI) benefits vary strikingly across European countries, see Figure 19.1. They are defined as the share of all individuals aged 50 to 64 who receive benefits from DI. With $15.6 \%$ and $11.6 \%$ the Nordic countries Sweden and Denmark have fairly high recipiency rates. The Central European countries cover a broader range. The rate of the Netherlands is $14.0 \%$ and thus similar to the Nordic countries while in France only a $1.7 \%$ of the people receive DI benefits. In the Mediterranean countries lower rates can be observed varying from $3.3 \%$ in Greece to $9.0 \%$ in Spain. The Eastern European countries exhibit the highest recipiency rates. While the Czech Republic with $12.3 \%$ is in a range with Denmark or the Netherlands, the Polish rate of $19.2 \%$ exceeds the rest by far.

Figure 19.1: DI recipiency rate in 13 European countries 


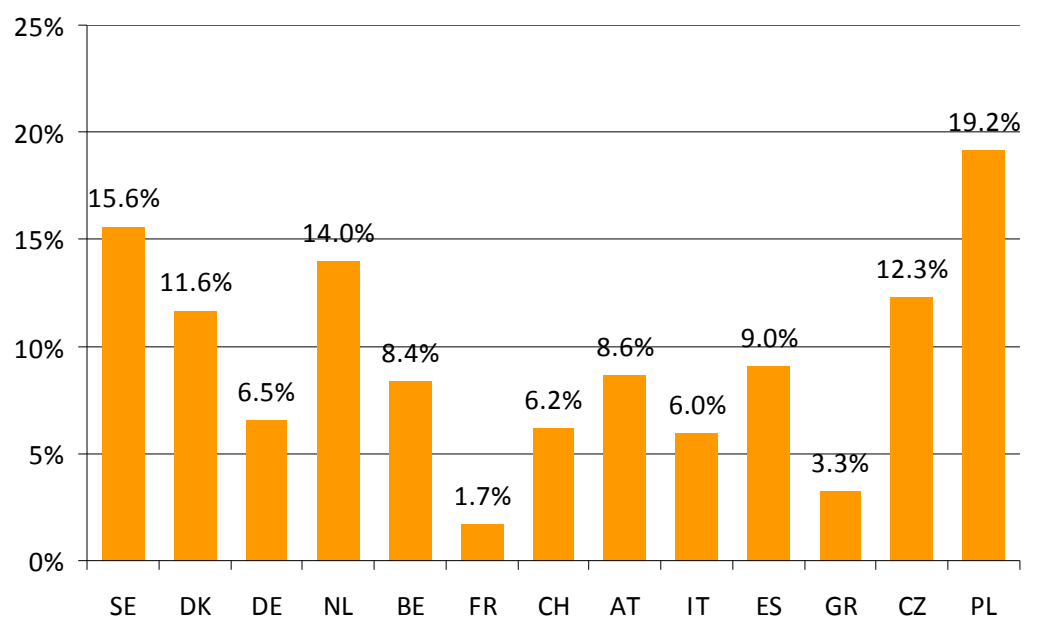

Source: SHARE wave 2 (2007), population weighted data

Why are so many more individuals aged 50-64 receiving DI benefits in Denmark, Sweden and the Netherlands than in e.g. France or Germany? Why so many fewer individuals in Greece than in Poland? This chapter investigates the causes for this variation. Three candidate causes come to mind: cross-national differences in the age structure, cross-national differences in health, and cross-national differences in the early retirement incentives created by the DI system. In earlier work based on the 2004 waves of SHARE, ELSA and HRS, we showed that cross-sectional differences in demographic structure and current health status cannot explain the cross-national differences in DI recipiency (Börsch-Supan, 2005) although health explains a great deal of the within-country variation (see also Avendano and Mackenbach in this volume). A second stage of our research was based on two waves of data. We showed that health events between waves did not significantly trigger a higher probability of becoming a DI benefit recipient (Börsch-Supan, 2008).

The poor explanatory power of a broad battery of health measures used in these studies, including objective and subjective measures as well as performance measures of physical and mental health, is disturbing and undermines the role of DI as an insurance of last resort against failures of health in working age. It has been criticized, however, that current health measures, as broad as they may be measured, do not appropriately capture the full impact of poor health on employability. Rather, it is argued, work disability is the result of a long lasting process of becoming sick and finally unable to work.

This paper therefore takes a life-course approach. Thanks to the new SHARELIFE dataset, we are able to add to the analysis a set of variables that account for those long-run effects. We first create lifetime health indicators that describe childhood and adulthood health status. In addition, we take other life-course 
features into account such as childhood socio-economic status, quality of the working place and marital status over the whole life course.

In the following section, we will briefly describe our approach. We then present our results at the individual level. We find that both current and life-course health significantly influences the probability of receiving DI benefits. We then turn to the cross-national level. We find that welfare state differences dominate at this level while cross-national health differences remain largely irrelevant even when taking life-course health measures into account.

\subsection{Variables and technique}

We focus our analysis on people at the age between 50 and 64 because this is the time span in which exiting the labour market via DI may be an attractive opportunity for early retirement. Beginning with age 65 , normal retirement benefits are available in all 13 countries in our analysis. The baseline of analysis is the year 2007. We have a large number of 10,385 observations, on average 800 in each country, with substantial differences across countries. Our dependent dummy variable is the recipiency of DI benefits. Following the three candidate causes and distinguishing current status from life-time influences, we employ five categories of variables:

1. Current basic demographic characteristics: age, gender and years of education.

2. A broad range of variables describing current health: self-perceived health, functional physical status described by the number of limitations in activities of daily living (ADL) and limitations of instrumental activities of daily living (IADL), mental health status as measured by EURO$\mathrm{D}$, grip strength as indicator of physical performance.

3. Life course health indicators include childhood health status and adulthood health status. Childhood health is described by the number of illnesses lived through until the age of 15 . For adulthood health a similar measure is taken, and in addition a binary variable indicating if someone had suffered from an extended period of poor health. Moreover, we include the number of gaps in the working history in which a person was sick or disabled.

4. Life course control variables include childhood socio-economic status, work quality and marital status. The socio-economic status during childhood is measured by the number of books, rooms per person in the accommodation and relative skills in mathematics at the age of ten. Work quality is measured as the subjective assessment of the physical and psychological demands at work. We also account for the number of jobs during lifetime. Finally, we include binary variables indicating if someone has been married, divorced or widowed during her or his lifetime. 
5. Variables describing the generosity of the welfare system regarding DI and alternative pathways are taken initially from OECD (2003). We have updated and extended these indicators to the countries not covered by the OECD. In general the OECD gives scores from 0 to 5 whereat a higher score represents a more generous system. At DI coverage 5 points are given if the DI covers the whole population while 0 points represents coverage only for employees. The minimum disability level that is required to be eligible is measured as percentage measure of work disability. The lower the percentage required the higher the score given. The maximum benefit level is measured as a replacement rate. A higher rate leads to a higher score. The strictness and whether DI benefit eligibility requires a medical assessment or whether a vocational assessment is sufficient is also included in the analysis. Finally, we insert a measure for the strictness of the unemployment insurance as an alternative pathway of early retirement.

Our analysis is divided into two parts. First, we relate at the individual level whether a person receives DI benefits to the above set of explanatory variables. We do this by pooling the SHARELIFE data from all countries and performing probit, logit and linear regression analyses. We also assess how much total variation in DI benefit recipiency at the individual level is explained by the different categories of variables.

Second, we analyze the cross-national variation depicted in Figure 19.1. To do so, we perform simulations which hold some of the explanatory variables counterfactually constant. If this group of variables were the main cause for the international variation, the simulated outcome should produce roughly identical percentages of DI benefit recipiency in each country.

\subsection{Regression results at the individual level}

Since the dependent variable - receipt of DI benefits - is binary we begin with a probit and a logit specification. Only the probit results are shown below since they yield very similar results explaining about $23 \%$ of the total variation (measured as the pseudo $\mathrm{R}^{2}$ ) which is quite a satisfactory value at the individual level. We also used a linear specification because it delivers essentially the same regression results (although on a different scale) and permits a more straightforward way to decompose the total variance.

All five categories of variables are jointly statistical significant: the corresponding F-test values are 23.4 for demographic variables, 208.6 for current health measure, 29.6 for the welfare state indicators, 201.9 for life-course health and 90.3 for all other life-course variables. Table 19.1 presents the results for the probit and linear specification. For the probit model, marginal effects are shown rather than the regression coefficients. 
Age and years of education have a negative effect on the receipt of DI benefits. Hence, older individuals have a smaller probability of receiving DI benefits. This may sound counterintuitive since health declines as we age. However, we control for health, see below, and alternative retirement pathways become available at older ages. More educated individuals are less likely to receive DI benefits. Male individuals are more frequently DI benefit recipients than female.

All current health measures have the expected sign and are significant, except for the number of ADL limitations. A dummy variable of the presence of ADL limitations, however, is significant. Better health leads to a lower probability of receiving DI benefits. As a remarkable result, we find that the more subjective a health measures is, the stronger is its influence. This may be an indication of some extent of self-justification (see Banks et al., 2004).

The life-course health variables show a clear picture. All life course indicators describing long-term health show the expected direction. Moreover, these variables are highly significant jointly but also each for itself as it can be seen in the table above. This result is robust over all three specifications. The variable describing childhood health is not significant.

Table 19.1: Determinants of DI recipiency

\begin{tabular}{|c|c|c|c|c|}
\hline \multirow[t]{2}{*}{ Variables } & \multicolumn{2}{|c|}{ Probit } & \multicolumn{2}{|c|}{ Linear } \\
\hline & $\begin{array}{l}\text { Marginal } \\
\text { effects }\end{array}$ & $\begin{array}{l}\text { Standard } \\
\text { error }\end{array}$ & Coefficients & $\begin{array}{l}\text { Standard } \\
\text { error }\end{array}$ \\
\hline Age (years) & -0.001 & $(0.0006)$ & $-0.001 * *$ & $(0.0006)$ \\
\hline Gender (dummy) & $-0.044^{* * *}$ & $(0.0070)$ & $-0.056 * * *$ & $(0.0082)$ \\
\hline Education (years) & $-0.002^{* * *}$ & $(0.0007)$ & $-0.002 * *$ & $(0.0007)$ \\
\hline Self-perceived Health (1-5) & $0.038 * * *$ & $(0.0028)$ & $0.039 * * *$ & $(0.0030)$ \\
\hline ADL (0-6) & 0.002 & $(0.0050)$ & 0.022 & $(0.0140)$ \\
\hline IADL (0-7) & $0.025 * * *$ & $(0.0046)$ & $0.067 * * *$ & $(0.0125)$ \\
\hline Maximal Grip Strength (kg) & $-0.001 * * *$ & $(0.0003)$ & $-0.001 * * *$ & $(0.0004)$ \\
\hline EURO-D (0-12) & $0.004 * * *$ & $(0.0012)$ & $0.005^{* * *}$ & $(0.0016)$ \\
\hline Childhood IIInesses (0-7) & -0.003 & $(0.0027)$ & -0.005 & $(0.0031)$ \\
\hline Adulthood IIInesses (0-5) & $0.017 * * *$ & $(0.0026)$ & $0.037 * * *$ & $(0.0058)$ \\
\hline Working Gaps due to Sickness (0-2) & $0.052 * * *$ & $(0.0114)$ & $0.118 * * *$ & $(0.0301)$ \\
\hline Period of very poor Health (dummy) & $0.056 * * *$ & $(0.0051)$ & $0.060 * * *$ & $(0.0061)$ \\
\hline Rooms per Person & -0.003 & $(0.0065)$ & -0.002 & $(0.0030)$ \\
\hline Number of Books (dummy) & -0.002 & $(0.0055)$ & -0.002 & $(0.0056)$ \\
\hline Mathematical Skills (dummy) & -0.007 & $(0.0052)$ & -0.005 & $(0.0050)$ \\
\hline Number of Jobs & $-0.003 * * *$ & $(0.0013)$ & $-0.005 * * *$ & $(0.0013)$ \\
\hline
\end{tabular}




\begin{tabular}{lllll}
\hline Physical Demand of Work (dummy) & $0.022^{* * *}$ & $(0.0053)$ & $0.024^{* * *}$ & $(0.0062)$ \\
Psychological Demand of Work (dummy) & -0.005 & $(0.0049)$ & -0.007 & $(0.0051)$ \\
Married (dummy) & -0.013 & $(0.0089)$ & $-0.019^{*}$ & $(0.0105)$ \\
Divorced (dummy) & $0.012^{*}$ & $(0.0063)$ & $0.015^{* *}$ & $(0.0072)$ \\
Widowed (dummy) & 0.005 & $(0.0094)$ & 0.005 & $(0.0109)$ \\
Coverage (0-5) & $0.010^{* * *}$ & $(0.0030)$ & $0.011^{* * *}$ & $(0.0036)$ \\
Minimum Disability Level (0-5) & $0.010^{* * *}$ & $(0.0027)$ & $0.009^{* * *}$ & $(0.0025)$ \\
Replacement Rate (0-5) & $-0.007^{* *}$ & $(0.0029)$ & $-0.006^{* *}$ & $(0.0027)$ \\
Medical Assessment (0-5) & $0.005^{*}$ & $(0.0025)$ & $0.007^{* * *}$ & $(0.0028)$ \\
Vocational Assessment (0-5) & $-0.017^{* * *}$ & $(0.0028)$ & $-0.017^{* * *}$ & $(0.0034)$ \\
Unemployment Benefits (0-5) & $0.013^{* * *}$ & $(0.0043)$ & $0.014^{* *}$ & $(0.0055)$ \\
Constant & & & $0.125^{* *}$ & $(0.0599)$ \\
\hline
\end{tabular}

$* * *, * *, *$ : Significant at $1 \%, 5 \%, 10 \%$, respectively.

Among the other life-course variables, the only significant ones are the subjective physical demand of work, the number of jobs and the binary variable describing if someone has been already divorced. Higher physical demand of the work leads to a higher probability of receiving benefits while an increase in the number of jobs leads to a decline in the reception of DI benefits. Suffering from at least one divorce increases the probability of being eligible.

The OECD indicators describing the generosity of the welfare system regarding DI and alternative pathways vary only across countries. They are nevertheless jointly significant and have, besides the replacement rate, the expected direction: the more generous the DI, the higher the probability of receiving the benefits. The broader the job range of vocational assessment, the less likely is the receipt of DI benefits. Strict eligibility rules and a low replacement rate of the unemployment insurance, a possible alternative pathway to retire early, increase the likelihood of receiving DI benefits.

Figure 19.2 shows how much variation at the individual level is explained by each of the five groups of variables, for simplicity using the linear regression model. The full linear model explains some $14.65 \%$ of the variation in the data. Basic demographic characteristics and education explain less than $1 \%$ of the individual variation. The OECD indicators vary only across countries and therefore explain, by definition, very little at the individual level. Current health measures have the largest explanatory power with over $9 \%$ of the individual variation explained. Life-course health variables are almost as powerful and explain $7.2 \%$ of the individual variation, while the other life-course variables explain $6.5 \%$. These results are in line with the findings by Avendano and Mackenbach in this volume.

Figure 19.2: Explanatory power of variable groups (in \% of explained variation) 


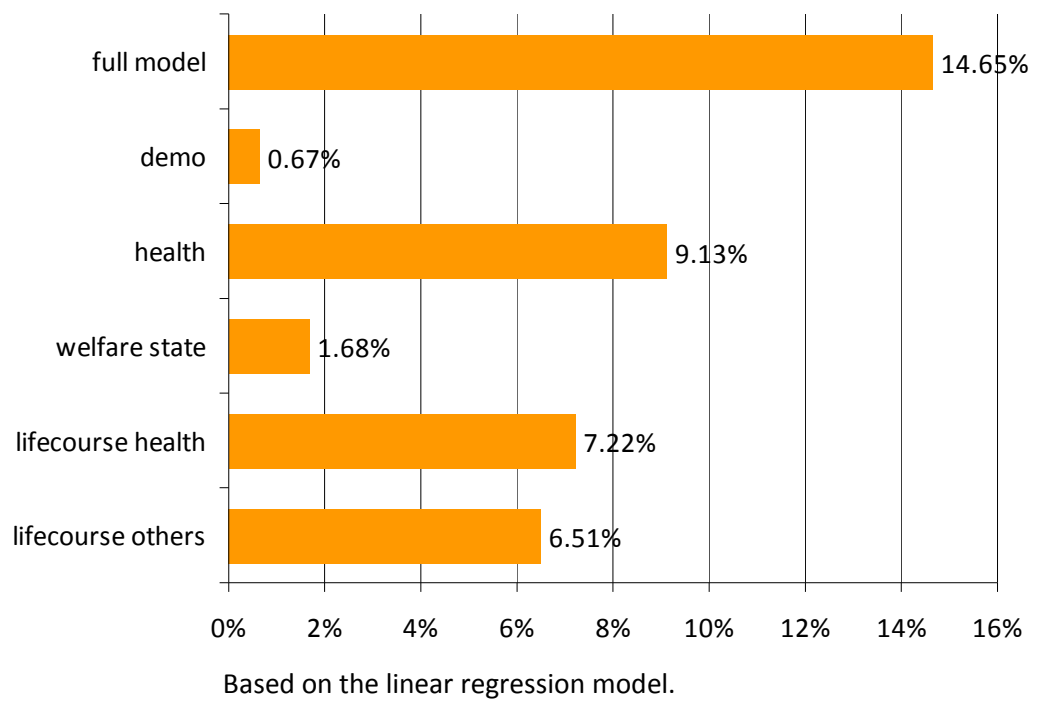

Quite clearly, both current and life-course health are highly predictive of receiving DI benefits at the individual level. Together, the health variables explain $12.4 \%$ of the total variation, i.e. $85 \%$ of the explained variation. Self-rated health is far the strongest single health variable, explaining $6.8 \%$ of the total variation.

\subsection{Counterfactual simulations at the country level}

This decomposition is dominated by intra-country individual variation and therefore does not shed much light on the large variation across countries. In order to separate cross-national from within-country variation, we predict DI recipiency rates at the country level with a counterfactual simulation which sets potential explanatory variables at the same level (usually the sample average) for all individuals across all countries. If a group of variables were the main driver of crossnational differences of DI recipiency, then equalizing these variables should also equalize the DI recipiency rates.

We perform three sets of such counterfactual simulations. The first set reproduces the results of Börsch-Supan (2005) with the 2007 data. It equalizes the demographic structure (i.e., all individuals are counterfactually assigned the same age, gender and number of years in education) and health. Figure 19.3 shows the resulting counterfactual cross-national distribution of DI recipiency rates.

The second bar for each country in Figure 19.3 equalizes age, gender and education across countries. Quite clearly, the resulting counterfactual DI benefit recipiency rates are virtually identical to the actual rates, represented by the left bar. 
Hence, age, gender, and education differences across countries can be ruled out as drivers of the cross-national variation in DI recipiency.

Figure 19.3: $\quad$ Demography and health

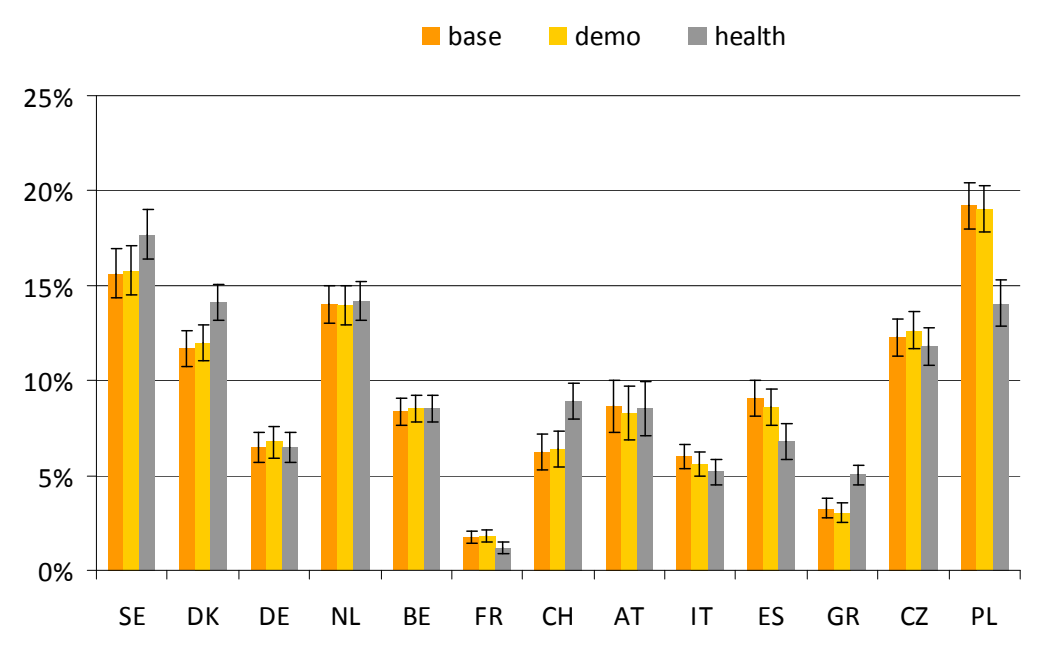

Simulation based on linear regression model. Brackets denote standard errors.

The right bar equalizes all current health measures. In countries with a relatively low level of health (especially Poland) and in Switzerland, where health is particularly high, we can indeed attribute some of the cross-national variation in DI benefit recipiency to health since the counterfactual prediction puts these countries closer to the average. The opposite, however, is true for those three countries in the EU15 in which benefit recipiency rates were particularly high in 2007: Sweden, Denmark, and the Netherlands. For these countries, correcting for health exacerbates the cross-national differences rather than levelling them off. Moreover, e.g. in Germany, measurements of objective health turn out to be better than the European average, while self-rated health is reported to be lower than the European average. Equalizing both objectively measured and self-rated health thus compensates each other. The opposite can be observed in Belgium. In summary, except for Poland, Greece and Switzerland, current health is not a main driver of cross-national variation in DI recipiency. This is a remarkable result as DI recipiency should be linked to work disability and thus health.

Current health, however, even if broadly measured, may be too narrow a health measure to determine the probability of receiving DI benefits because health events which took place much earlier in life may have driven the transition out of work. Possible influences are multi-dimensional. There may be direct effects of childhood diseases that have undermined resilience in old age and then lead to a disability. There may also be indirect effects of childhood diseases that worsen 
adult health at earlier stages. Often, disabilities are the result of long periods of illness and suffering from physical or mental impairments. Current health measures cannot reflect such long-term developments. Moreover, there may be other childhood living conditions such as socio-economic status that may build the background for later health problems and disability.

We take account of these possibilities by performing a second set of counterfactual simulations, now equalizing the life-course health and other life-course variables available in the SHARELIFE data, such as indicators for socio-economic status, marital history and work satisfaction.

Figure 19.4: Life-course health and other life-course factors

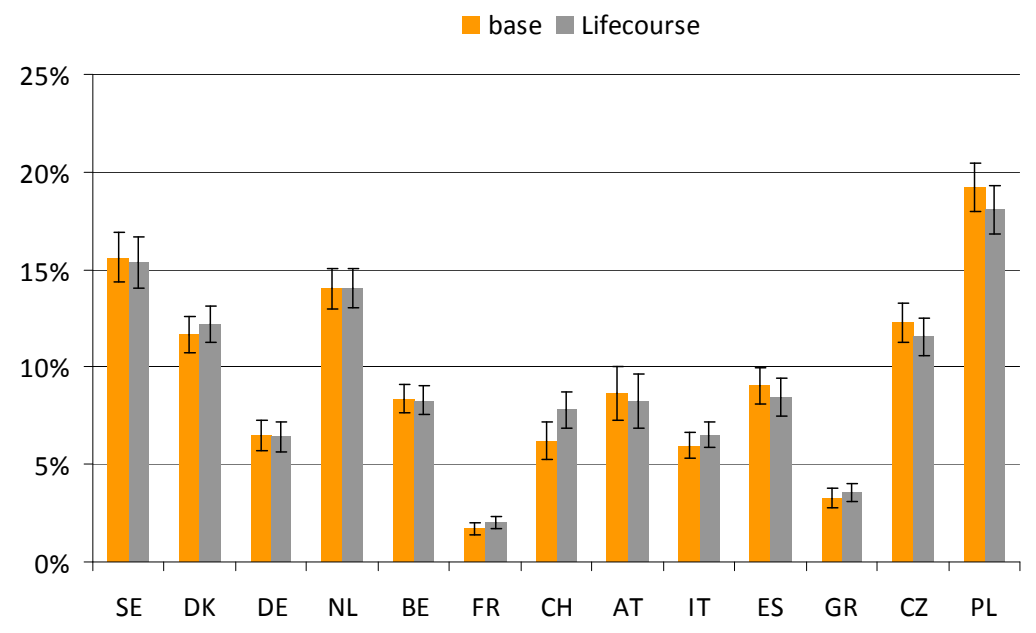

Based on the linear regression model. Brackets denote standard errors.

Figure 19.4 presents the results. They are unambiguous: life-course variables do not explain the cross-national variation. Not a single difference is statistically significant.

So far, we have ruled out demographics, education, current and life-course health and other life-course characteristics as causes for the cross-national differences in DI benefit recipiency. Among the variables discussed in the introduction, institutional features and their incentives created remain as another potential cause. Our third set of counterfactual simulations therefore equalizes all variables that describe the generosity of the DI system and potential alternative pathways, such as unemployment insurance.

Figure 19.5 shows that actual and simulated now diverge considerably. Except for Switzerland and Poland, the simulated recipiency rates of DI benefits are much more equal across countries when we assume the same institutional framework in every country. Most importantly and as opposed to Figure 19.3, those three coun- 
tries in the EU15 in which benefit recipiency rates were particularly high in 2007 - Sweden, Denmark, and the Netherlands - now exhibit much smaller DI rates when the generosity of their DI systems is reduced to the average level across the 13 included countries.

Figure 19.5: Welfare state generosity

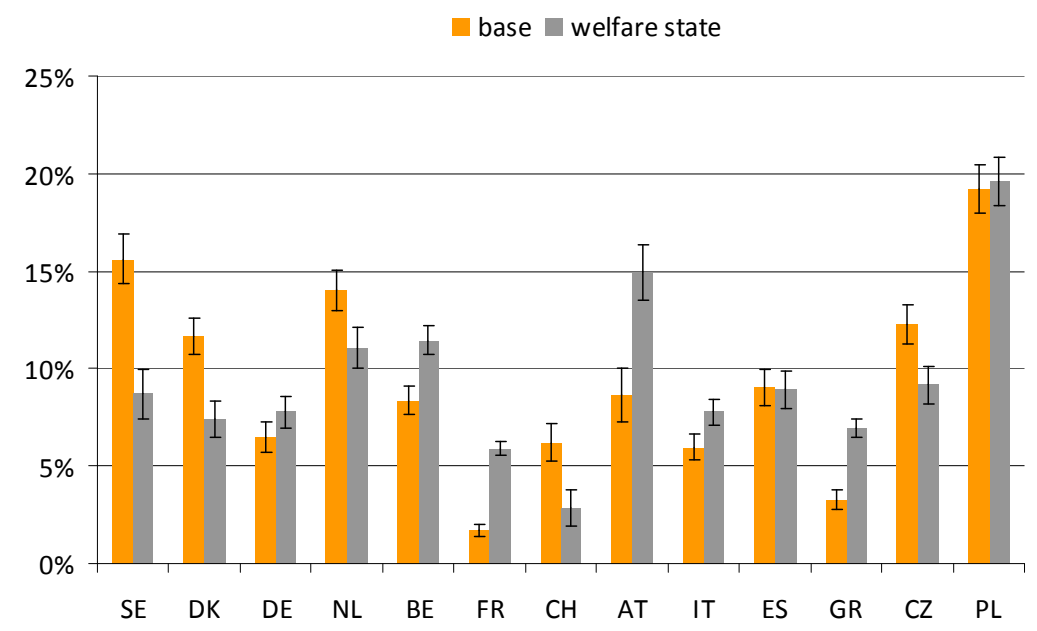

Simulation based on linear regression model. Brackets denote standard errors.

\subsection{Discussion and conclusions}

In assessing our results, it is important to distinguish individual level variation from cross-national variation. Since we have more than 10,000 observations and only 13 countries, our regression results (Table 1) are dominated by the withincountry variation. Here, both current and life-course health variables are highly significant both jointly and each for itself at the individual level. This shows that these variables are reliable measures of health, and they indeed contribute to about $85 \%$ of the overall explained variation across individuals. Variables describing the welfare state, however, especially the generosity of the DI system, cannot determine within a country if someone receives DI benefits because all individuals face the same DI system.

In our counterfactual simulations (Figures 19.3, 19.4 and 19.5), we only see the cross-national variation. At this level, the roles of health and DI system generosity switch completely. Neither current nor life-course health can be identified as a source of cross-national variation in the DI recipiency rates, while variables describing the generosity of the DI system have strong explanatory power. This ex- 
planatory power is driven by the large differences in DI generosity across countries as described by the OECD indicators.

This leads to a threshold interpretation (Croda and Skinner, 2009): Our broad set of health variables rank individuals well by health within each country. The thresholds, however, beyond which DI benefits are granted, are country-specific and have almost no relation to health. They are products of institutional characteristics such as minimum benefit levels and assessment requirements.

\section{References}

Aarts, L. J. M., R. V. Burkhauser, and P. R. de Jong (eds) (1996): Curing the Dutch disease. An international perspective on disability policy reform. Aldershot, Avebury.

Banks, J., A. Kapteyn, J.P. Smith, A. van Soest. (2004): International Comparisons of Work Disability, RAND Working Paper, WP-155.

Börsch-Supan, A. (2005): Work Disability and Health. In: A. Börsch-Supan et al. (eds.), Health, Ageing, and Retirement in Europe - First Results from the Survey of Health, Ageing and Retirement in Europe. Mannheim, pp. 253-258.

Börsch-Supan, A. (2008): Changes in Health Status and Work Disability. In: A. Börsch-Supan et al. (eds.), Health, Ageing, and Retirement in Europe - Starting the Longitudinal Dimension. Mannheim, pp. 228-236.

Croda, E., and J. Skinner (2009): Disability Insurance and Health in Europe and the US, Paper prepared for the SHARE User Conference, October 2009, Mainz, Germany.

OECD (2003): Transforming Disability into Ability. Paris. 